\title{
The Effectiveness of Gastrografin Study and Multidetector CT Study in Evaluation of Early Complications of Laparoscopic Sleeve Gastrectomy Complications
}

\author{
MOMENA ESSAM ELSADAWY, M.D. \\ The Department of Radiodiagnosis and Nucleur Medicine, Faculty of Medicine, Ain Shams University
}

\begin{abstract}
Background: Laparoscopic sleeve gastrectomy is a relatively recent surgical technique that was estimated to account for about $5 \%$ of all bariatric surgery. Post-operative complications detection could be done by either fluoroscopic gastrografin meal or multislice CT study before and after contrast administration.
\end{abstract}

Aim of Study: To compare between the effectiveness of the main imaging modalities of early post-operative complications of laparoscopic gastric sleeve surgery, including fluoroscopic gastrografin meal and multislice CT study.

Patients and Methods: The study included 150 patients; 128 females $(85 \%)$, and 21 males $(15 \%)$. Their ages ranged from 26 to 55 years with mean age about 41 years. Patients were selected based on clinical suspicion of post-operative complications. Fluoroscopic gastrographin study and multidetector CT study have been done. Operative findings correlation and clinical follow-up were the standard of reference.

Results: Forty (30\%) patients had matched fluoroscopic and CT findings, 110 (70\%) patients had positive CT findings but, negative fluoroscopic findings. $0 \%$ had positive fluoroscopic findings and negative $\mathrm{CT}$ findings.

The leak was suspected in 80 patients, 5 patients with active bleeding that was clinically suspected, but the exact site of bleeding could not be identified by CT, 37 patients had serous fluid collection, splenic infarction was noticed in 5 patients, 3 patients developed post-operative hematoma one of them become infected, anterior abdominal wall hematoma seen in 5 patients, one patient developed portal vein thrombosis.

Conclusion: Multidetector CT is better imaging modality in precise detection of early post laparoscopic sleeve gastrectomy complications than fluoroscopic gastrografin imaging.

Key Words: CT-Laparoscopic sleeve gastrectomy (LSG) Fluoroscopic gastrografin meal.

\section{Introduction}

OBESITY is a disease that has reached epidemic proportions around the world. Obesity is measured

Correspondence to: Dr. Momena Essam Elsadawy, E-Mail: Momena.essam@yahoo.com by Body Mass Index (BMI), a value based on a combination of weight and height (BMI=weight [kilograms]/height [meters $]^{2}$ ). Overweight is defined as a BMI of $25-29 \mathrm{~kg} / \mathrm{m}^{2}$, obesity is defined as a BMI of $30-35 \mathrm{~kg} / \mathrm{m}^{2}$, and morbid obesity is defined as a BMI of greater than $35-40 \mathrm{~kg} / \mathrm{m}^{2}$. Bariatric surgery is by far the most invasive form of therapy for obesity, so it is ideally reserved for patients who fail to lose weight with diet, exercise, and behavioral modification. Despite these guidelines, the use of bariatric surgery has increased dramatically [1].

During the past two decades, bariatric surgery has become an increasingly popular form of treatment for morbid obesity. The most common bariatric procedures performed include laparoscopic Roux-en-Y gastric bypass, laparoscopic adjustable gastric banding, and laparoscopic sleeve gastrectomy [1].

Fluoroscopic upper gastrointestinal examinations and contrast enhanced abdominal Computed Tomography (CT) are the major imaging modalities used to evaluate early post-operative changes.

The main aim of this research is to evaluate the acute post-operative acute complications after laparoscopic gastric sleeve include mainly anastomotic leaks and strictures, post-operative collection and haematoma, there are many acute complications associated with LSG such post-operative leaks or bleeding, abscess formation, splenic infarction and portal vein thrombosis [2].

\section{Laparoscopic sleeve gastrectomy:}

Laparoscopic sleeve gastrectomy is a relatively recent surgical technique introduced in 1999. This procedure was estimated to account for about $5 \%$ of all bariatric surgery in 2008. Sleeve gastrectomy 
is a procedure in which a long, narrow gastric pouch is created by removing about $75 \%$ of the stomach, promoting weight loss by the restrictive effect of the pouch [3].

\section{Surgical anatomy:}

Sleeve gastrectomy is performed laparoscopically by dividing the stomach along its long axis and resecting the greater curvature of the fundus, body, and proximal antrum, producing a narrow, banana-shaped gastric pouch along the lesser curvature Fig. (1). The remaining stomach has a residual volume of only about $100 \mathrm{~mL}$, causing the patient to experience early satiety and weight loss [3].

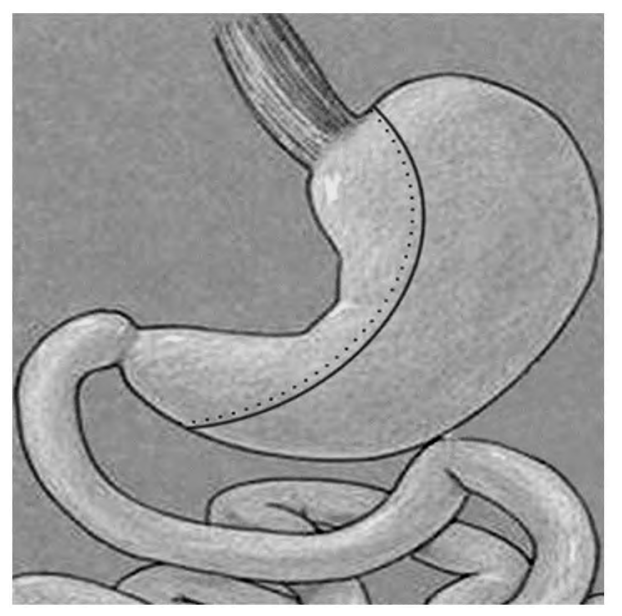

Fig. (1): Diagram shows normal surgical anatomy after laparoscopic sleeve gastrectomy. Note how stomach is resected along greater curvature of fundus, body, and proximal antrum, producing a narrow, bananashaped pouch along lesser curvature (3).

The main imaging modalities for evaluation of early post-operative complications are fluoroscopic gastrografin meal and multislice contrast enhanced CT study.

The aim of this study is to compare between the effectiveness of the main imaging modalities of early post-operative complications of laparoscopic gastric sleeve surgery, including fluoroscopic gastrografin swallow and multislice CT study.

\section{Patients and Methods}

\section{Patients:}

This was a prospective study that was conducted in the Radiology Department of private hospital, in collaboration with the Bariatric Surgery Department, from April 2019 till August 2019.

The study included 150 patients; 128 females $(85 \%)$, and 21 males $(15 \%)$. Their ages ranged from 26 to 55 years with mean age about 41 years.
Patients were selected based on clinical suspicion of post-operative complications. Fluoroscopic gastrografin study and multidetector CT study have been done. Clinical correlation and follow-up were the standard of reference.

The study was approved by the Local Ethics Committee.

Consent was taken from all patients according to the hospital and research committee policy.

Patients' selection was based on clinical suspicion of early post-operative complications including mainly leakage and haematoma.

\section{Inclusion criteria:}

- Any gender.

- Adult age group.

- Patients who did laparoscopic sleeve gastrectomy and developed post-operative complaints like abdominal pain and persistent vomiting shortly post-operative.

\section{Exclusion criteria:}

- Contraindications to contrast CT examination.

\section{Methods:}

The bariatric center in the hospital has multidisciplinary team consists of well trained surgeons, dietician, specialist nurses well trained radiologist and radiographers.

Patients with suspected post-operative complications have been scheduled to gastrografin meal using water soluble contrast media, 2:1 ratio of contrast media: Water dilution. Contrast enhanced CT study was also performed using Seimens 16row multidetector machine using water soluble iodinated contrast taken orally (low risk of chemical peritonitis), IV contrast injection (unless it is not contraindicated) performing triphasic CT when there is clinical suspicious of active bleeding or portal vein thrombosis.

\section{Normal imaging features:}

Upper GI examination-upper GI examinations typically reveal a long, tubular gastric pouch iwith reduced gastric capacity Figs. $(2,3)$. Because the distal gastric antrum is preserved, there may be a relatively abrupt segment of widening at the distal end of the pouch. Some patients may have transient retention of barium in the proximal end of the pouch because of loss of peristalsis during the early post-operative period [3] 


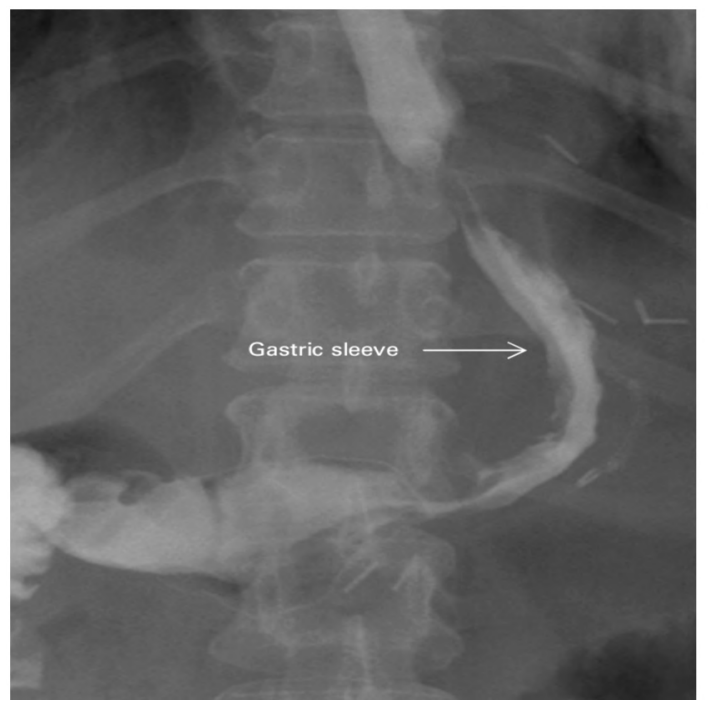

Fig. (2): Gastrografin meal post laparoscopic sleeve gastrectomy of 46 year-old male showing tubular stomach with reduced gastric capacity. Surgical staples are seen.

\section{Results}

Forty $40(25 \%)$ patients had matched fluoroscopic and CT findings, 25 patients with leakage and 15 patients with serous collection. $110(75 \%)$ patients had positive CT findings but, negative fluoroscopic findings. $0 \%$ had positive fluoroscopic findings and negative CT findings.

Table (1) illustrates different types of complications and their percentage.

Table (1): Different complications and their percentage.

\begin{tabular}{|c|c|c|c|c|}
\hline Complication & Number & Percentage & $\begin{array}{l}\text { Flouroscopic } \\
\text { findings }\end{array}$ & $\begin{array}{c}\text { CT } \\
\text { findings }\end{array}$ \\
\hline Leak & 80 & $53 \%$ & 25 & 55 \\
\hline Active bleeding & 5 & $3.5 \%$ & 0 & 5 \\
\hline $\begin{array}{l}\text { Post-operative fluid } \\
\text { collection }\end{array}$ & 37 & $24.5 \%$ & 15 & 12 \\
\hline Splenic infarction & 5 & $3.5 \%$ & 0 & 5 \\
\hline $\begin{array}{l}\text { Post-operative } \\
\text { hematoma }\end{array}$ & 3 & $2 \%$ & 0 & 3 \\
\hline Portal vein thrombosis & 1 & $0.5 \%$ & 0 & 1 \\
\hline $\begin{array}{l}\text { Anterior abdominal } \\
\text { wall hematoma }\end{array}$ & 5 & $3.5 \%$ & 0 & 5 \\
\hline
\end{tabular}

The leak was seen in 80 patients, 25 of which had positive flouroscopic and CT findings Figs. $(4,5)$. In 5 patients active bleeding was clinically suspected, but the exact site of bleeding could not be identified by CT, 37 patients had serous fluid collection, 15 of which had matched positive flouroscopic and CT findings.

Splenic infarction was noticed in 5 patients, 3 patients developed post-operative hematoma one

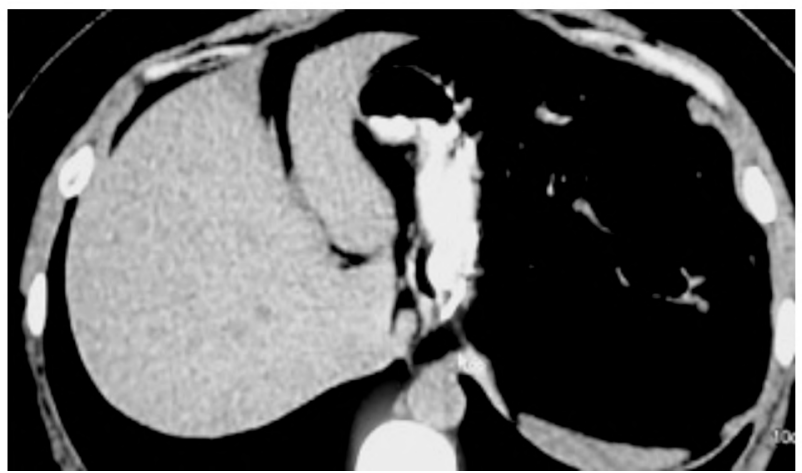

Fig. (3): Normal CT findings of 36 year-old female after sleeve gastrectomy show tubular narrowing of gastric pouch secondary to resection of greater curvature of proximal and mid stomach.

of them become infected, anterior abdominal wall hematoma seen in 5 patients, one patient developed portal vein thrombosis. 110 patients had negative flouroscopic findings, yet, contrast enhanced CT study revealed positive post-operative complications Fig. (6).

We had five patients diagnosed as active bleeding depending on the clinical picture they suffered from acute pain, and sudden drop of their hemoglobin. Two of them LSG was done with removal of gastric band that was left for one year and extensive fibrosis noticed during surgery (this explain the high incidence of bleeding in this patient), dedicated CT study with IV contrast injection showed increasing amount of free intraperitoneal fluid at the surgical bed and sub phrenic spaces Fig. (7) but exact site of bleeding could not be identified by CT.

Regarding leakage, diagnosis suspected clinically if abdominal pain and persistent vomiting developed. Eeighty patients showed a moderate amount of free intraperitoneal fluid in the left subphrenic space with retrogastric and perisplenic collection.

Serous collection at the upper part of the staple line and para splenic area noticed in 37 patients, no gases within it follow-up is recommended to ensure that abscess did not develop.

Five patients had post-operative haematoma, two of them was suture hematoma noticed along 
the mid portion of staple line Fig. (8), on followup it was retracted showing altered density with no fluid collection or leak, the other two show large hematoma beside the staple line and extends to splenic hillum Fig. (9), the fifth one was an intra operative hematoma at the gastroeosophgeal junction, follow-up 5 days later it become infected with the leak of oral contrast and air pocket inside.

Splenic infarction noticed in 5 patients all seen at the upper pole of the spleen Fig. (10).

Portal vein thrombosis seen in one patient 10 days post-operative Fig. (11). Anterior abdominal wall hematoma seen in 5 patients all was localized small related to the anterior sheath of rectus muscle or seen subcutaneously.
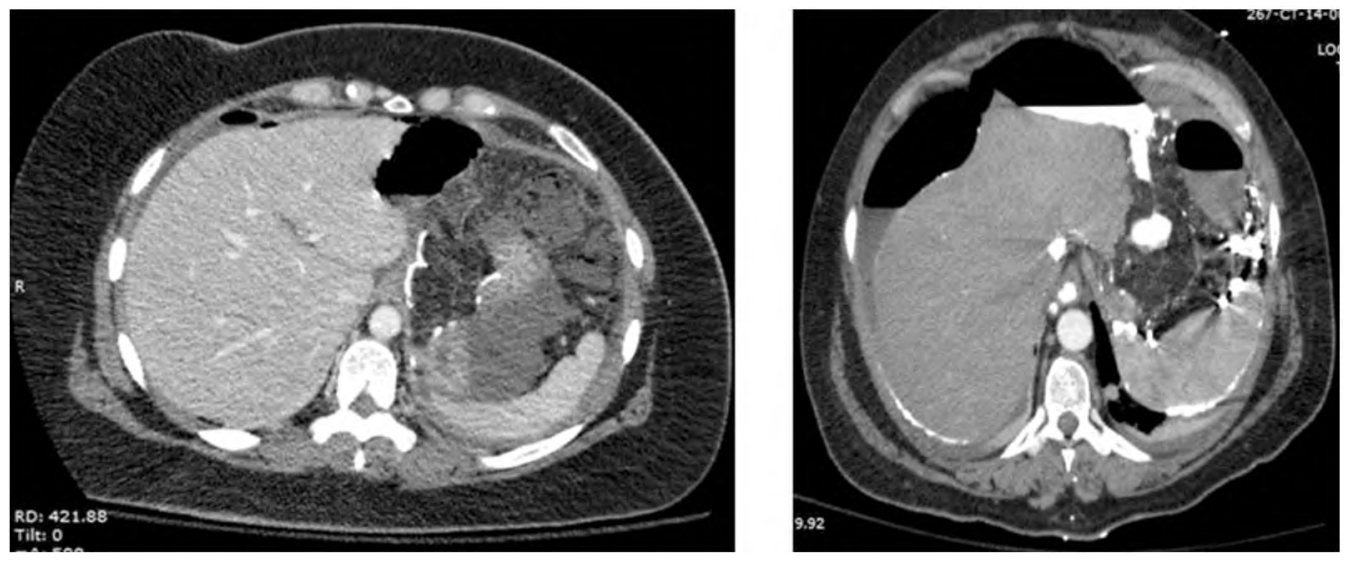

Fig. (5): Axial contrast CT post sleeve gastrectomy of the same patient showing contrast leak with a large amount of collection in gastosplenic recess, perisplenic and perihepatic free fluid as well as pneumoperitoneum.

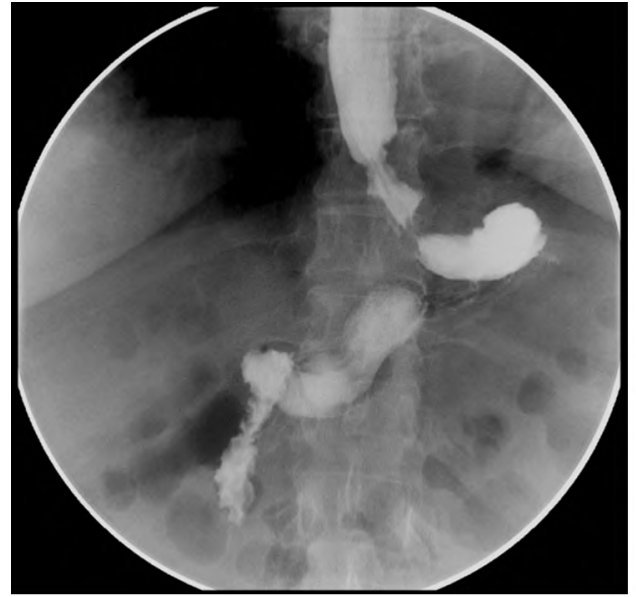

(A)

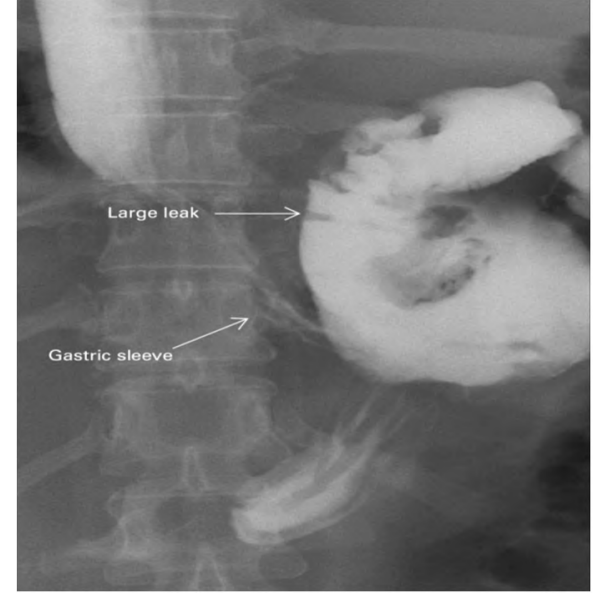

Fig. (4): Gastrografin meal two days post-laparoscopic gastric sleeve in 42 year-old male showing a large contrast leak at gastro-esophageal junction. 


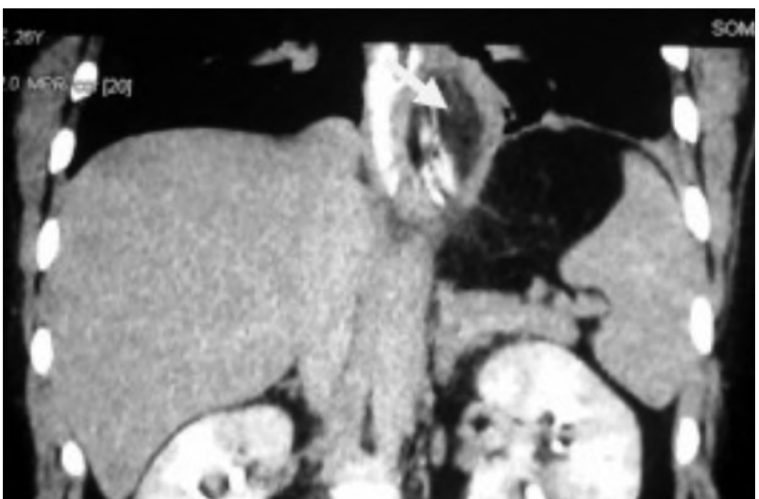

(A)

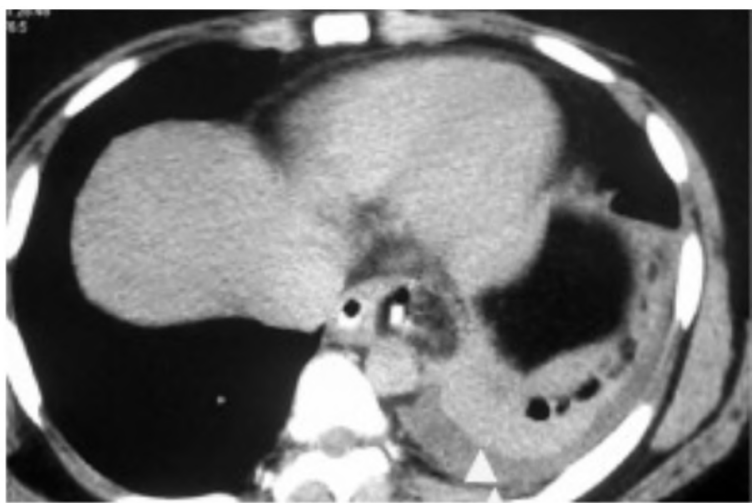

(B)

Fig. (7): Female patient, 33 years old post LSG, coronal (A) and axial (B) images show, well defined collection at the upper part of staple line with the lack of oral contrast inside and also air pockets seen (arrowed), left plural effusion noticed (head of the arrow). It was an intra-operative hematoma that became infected with the leak of oral contrast inside.
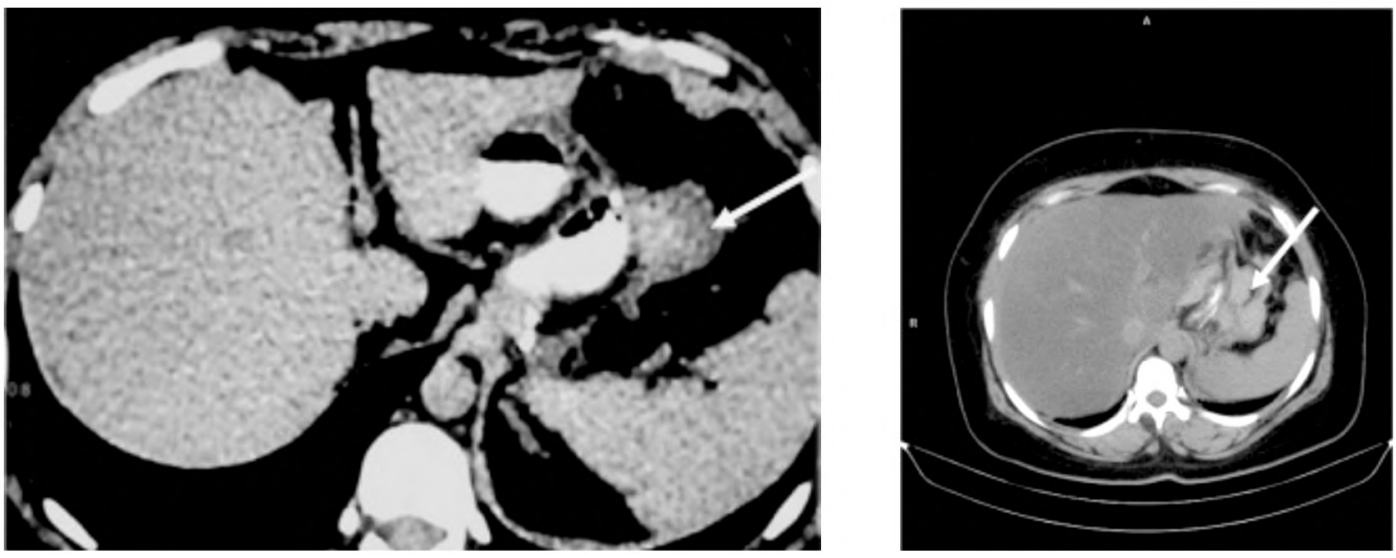

Fig. (8): Axial CT image post LSG show well define hematoma (white arrow) related to the mid third of the suture line, on CT follow-up, hematoma start to reduce in size and alter density.

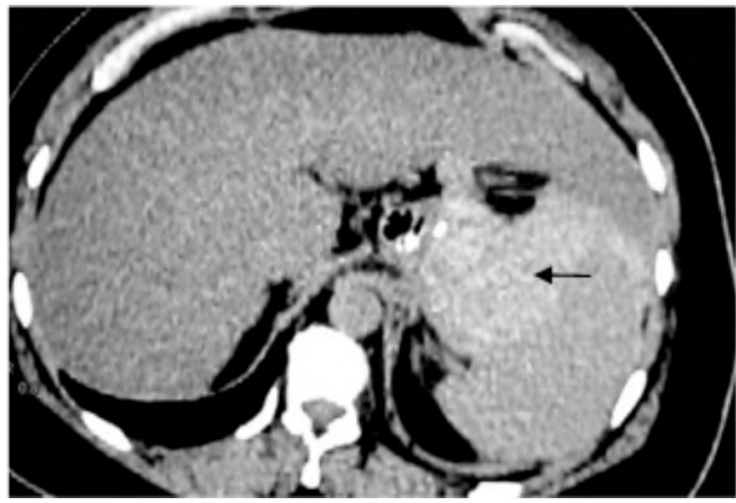

Fig. (9): Axial CT image post LSG show hyperdense hematoma at the surgical bed and extend to splenic hilum and the lower pole of the spleen (black arrow).

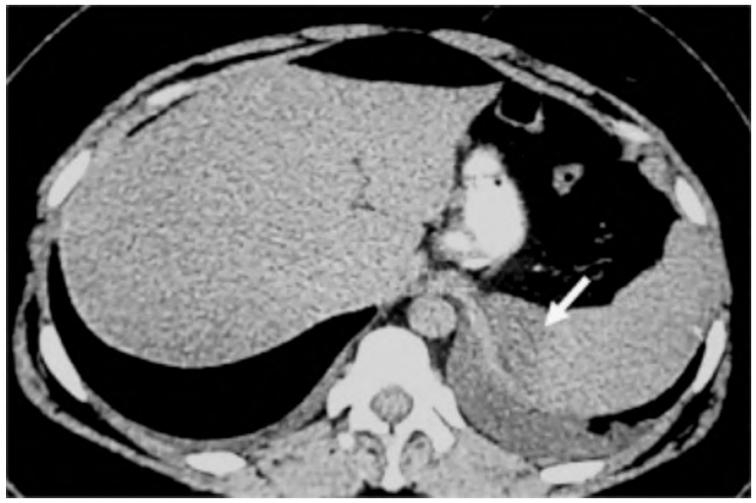

Fig. (10): CT axial cut post LSG shows an ill defined hypodense area of splenic infarction at the upper pole of the spleen (white arrow) associated with left plural effusion. 


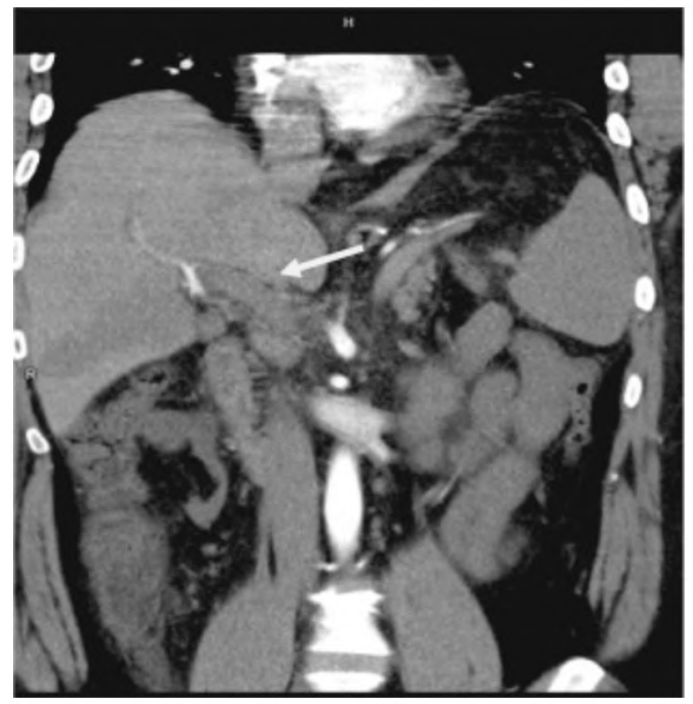

(A)

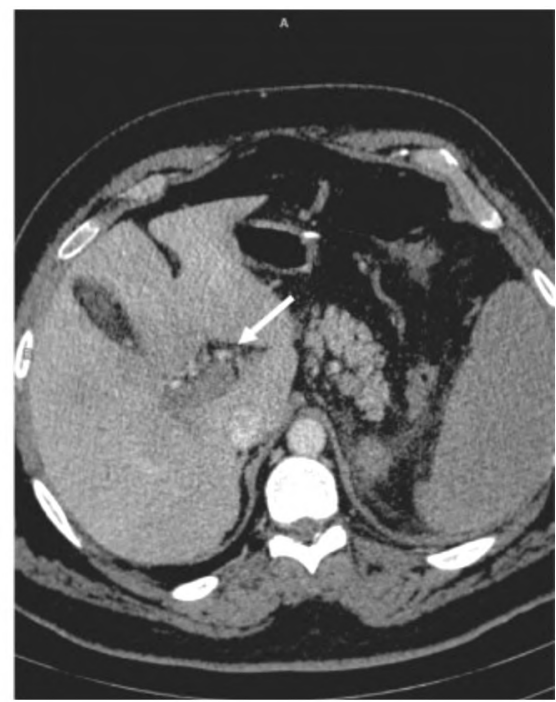

(B)

Fig. (11): Male patient, 29 years old post LSG, CT triphasic study axial and coronal images (portal phase) show; non opacified main portal vein and its right main branch (white arrow) it is seen also distended with hypodense venous thrombus.

\section{Discussion}

LSG becomes widespread and it now accounts for approximately $5 \%$ of Bariatric procedure [4] Post-operative complications are not uncommon, acute post-operative complications are those developed within one month post-operative. Flouroscopic gastrografin meal and contrast enhanced CT help to assess different types of those complications [5].

Leak is the most common complication due to the long staple line. The direct sign of a leak is contrast leak from the surgical site into the peritoneal cavity. In this study, direct leak sign noticed in thirty patients. Leak occur most likelyat the upper part of the staple line at the gastro-oesophgeal junction this is in agreement with many studies stated that mostly a collection occurs at the gastroesophageal junction and less common in the distal part of staple line [6].

Indirect signs of a leak are presence of gas bubbles and fluid collections next to the surgical site. Gas bubbles are a common post-operative sequelae finding during the first 5-7 days, later on they are unusual. In our study, thirty seven patients showed a collection of fluid at sub phrenic space. Those in agreement with Kim et al., [7], who explained that after the transaction of gastrocolic and gastrosplenic ligaments there is a communication between the lesser sac and the left subphrenic space. Chivot et al., [8] explained the early leak due to mechanical or technical errors while for late onset (within 5-7 days) due to ischemia caused by tension and poor wound healing and in both scenarios, the intraluminal pressure exceeds the potency of the tissues and staple lines resulting in a leak.

Unlike fluoroscopic gastrografin study, CT can differentiate between serous collection from an abscess. The serous collection is the collection of sterile fluid without walls, which is spontaneously absorbed in the immediate post-operative period and does not require any intervention [9]. Thirty seven cases in our study showdifferent amount of transudate but follow-up was done to ensure that it will not progress to abcess. Only one patient developed abscess formation actually it was infected hematoma 5 days post-operative there is well defined collection on the upper part of the staple line with the leak of oral contrast inside and air pocket, this patient managed by laparoscopy drainage.

The risk of post-operative bleeding has been reported to be between $1 \%$ and $6 \%$ after LSG $[10,11]$, the source of bleeding can be intra-or extraluminal. Extaluminal bleeding, suspected clinically by a serial drop in serum hemoglobin levels or signs of tachycardia or hypotension. Common sources of extraluminal bleeding include the gastric staple line, spleen, liver or abdominal wall at the sites of trocar entry [12]. In our study, there were five patients diagnosed as being active bleeding depending on the clinical picture and serial CT study showed an increasing amount of free intraperitoneal fluid at the site of surgery and subpherenic space with faint opacification on IV triphasic 
study, one of them shows upper pole splenic hematoma Fig. (4), the exact site of bleeding could not be identified by CT study. Patients managed conservatively. Another patient came with localized suture hematoma at the mid part of the staple line with no free fluid intraperitoneal. On follow-up, the hematoma retracted and CT density reduced. One patient shows large parasplenic hematoma, localized subcutaneous hematoma and anterior abdominal wall hematoma at the trocar site detected in 8 patients it appear as ill defined heterogeneous density lesion at the site of trocar entry related to the rectus sheath. Splenic infarction was detected in 18 cases and appeared as ill defined peripherally based hypodense area at the upper pole of the spleen, some cases there is localized minimal perisplenic rim of fluid adjacent to the infarct area. We agree with Hasan et al., [13] that splenic infarction may be explained by injury or occlusion of peripheral splenic arterial branches when the surgeon exposes the greater curvature and separately coagulates the short gastric vessels close to the spleen. Martinez et al., [14] explain some technical consideration for minimizing the risk of splenic infarct like dividing the SGVs as close to the stomach as possible to decrease the likelihood of dividing a splenic branch and careful dissection of the gastrophrenic ligaments at the angle of his and the left crus, over the gastroesophageal junction, and at the posterior aspect of gastric fundus. Portal vein thrombosis is an uncommon complication following laparoscopic Bariatric surgery, with potentially life-threatening consequences. Presenting symptoms are often vague, and a high index of suspicion is required to obtain the proper noninvasive imaging studies to confirm the diagnosis and begin prompt treatment. Although the cause of portal vein thrombosis after laparoscopy is unknown, it is established that increased intraabdominal pressure with pneumoperitoneum results in decreased portal venous blood flow, which may lead to a relative prothrombotic environment $[\mathbf{1 5 , 1 6}]$ where as gastric bypass involves some transection of the gastric and mesenteric veins causing endothelial damage, the sleeve gastrectomy involves transection of the short gastric veins alone, and is thus less likely to cause PVT [17]. Within the study population only one Sudanian patient had portal vein thrombosis discovered 10 days after surgery, he complains of abdominal pain, nausea the cause of thrombosis may be related to the type of dietary habits of this patient.

\section{Conclusion:}

Multidetector CT is better imaging modality in precise detection of early post laparoscopic sleeve gastrectomy complications than fluoroscopic gastrografin imaging.

\section{Conflict of interest:}

None.

\section{References}

1- MARIANA O., PABLO S., GERARDO B. and LILIANA S.: Imaging of post-operative complications of sleeve gastrectomy. Rev. Imagenol. 2da Ep. Jul. /Dic., 114-38, 2017.

2- MARC S. LEVINE and LAURA R. CARUCCI: Imaging of Bariatric Surgery: Normal Anatomy and Post-operative Complications. RSNA. Feb., 10-118, 2014.

3- S. SHAH, V. SHAH, A.R. and AHMED D.M.: Imaging in Bariatric surgery: Service setup, post-operative anatomy and complications, Br. J. Radiol., 84 (998): 101-11, 2011.

4- A.A. GUMBS, M. GAGNER, D. and DAKIN O.: Sleeve gastrectomy for morbid obesity Obes. Surg., 17: 962-9, 2007.

5- PÉREZ D., SCHIAPPACASSE G. and ZÚÑIGA F.: Gastrectomía en manga: Estudio por imagen de sus complicaciones, Rev. Chil. Cir., 67 (5): 554-9, 2015.

6- M. DEITEL, M. GAGNER, A. and ERICKSON: The second international consensus summit for sleeve gastrectomy, Surg. Obes. Relat. Dic., 5: 476-85, 2009.

7- K.W. KIM, B.I. CHOI, J.K. HAN, T.K. KIM and A.Y KIM: Post-operative anatomic and pathologic findings at CT following gastrectomy, AJR, 38: 145-60, 2017.

8- C. CHIVOT, B. ROBERT, N. LAFAYEA, D. FUKS, A. DHAHRI and P. VERHAEGHE: Laparoscopic sleeve gastrectomy: Imaging of normal anatomic features and postoperative gastrointestinal complications, Diagnostic Intervent Imaging, 94: 823-34, 2013.

9- BUCHWALD H. and OIEN D.M.: Metabolic/bariatric surgery worldwise 2008. Obes. Surg. 3 Nov., 19: 160511, 2009.

10- S.M. LEVINE and L.R. CARUCCI: Imaging of Bariatric Surgery: Normal anatomy and post-operative complications, Radiology, 270: 327, 2014.

11- E.E. FREZZA: Laparoscopic vertical sleeve gastrectomy for morbid obesity. The future procedure of choice? Surg. Today, 37: 275-81, 2007.

12- J. MELISSAS, S. KOUKOURAKI, and J. ASKOXYLAKIS.: Sleeve gastrectomy: A restrictive procedure? Obes. Surg., 17: 57-62, 2007.

13- A.H. TAMIR, M. NESREEN and WAEL H.K.: Clinicalradiologic evaluation of the complications of laparoscopic sleeve gastrectomy: Value of multidetector CT Egypt J. Radiol. Nucl. Med., 46: 879-84, 2015.

14- D.G. MARTÍNEZ, A.W. SÁNCHEZ and A.P. GARCÍA: Splenic abscess after laparoscopic Nissen fundoplication: a consequence of short gastric vessel division Surg. Laparosc. Endosc. Percutan Tech., 18: 82-5, 2008.

15- S. KOUROSH, W.B. DANIEL, S. ARYA and K SHAHZEER: Complications associated with laparoscopic sleeve gastrectomy for morbid obesity: A surgeon's guide, Can J. Surg., 56 (5): 347-52, 2013. 
16- J. JAKIMOWICZ, G. STULTIENS and F. SMULDERS:

Laparoscopic insufflations of the abdomen reduces portal venous flow, Surg. Endosc., 12: 129-32, 1998.
17- S. TAKAGI: Hepatic and portal vein blood flow during carbon dioxide pneumoperitoneum for laparoscopic hepatectomy, Surg. Endosc., 12: 427-31, 2000.

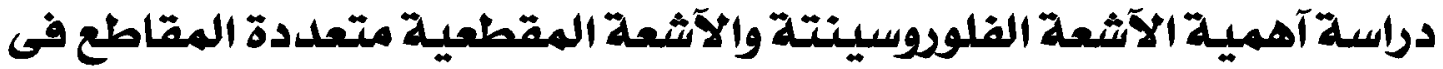

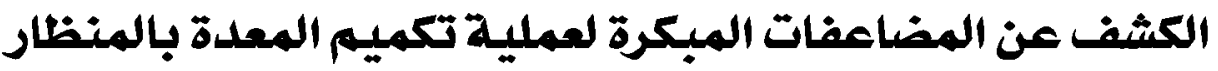

تعد عمليات السمنة من آحدث العمليات وآكثرها إنتشاراً فى الآونة الآخيرة. وتمثل عملية تكميم المعدة حوالى ٪٪ من هذه الإجراءات

وقد كان الهلف من إجراء هذا البحث هو مقارنة دور الآشعة الفلورسينتية والآشعة المقطعية متعددة اللواقط قبل وبعد الصبغة فى الكشف المبكر عن مضاعفات هذه العملية.

تم إجراء المقارنة بين • ال مريض تتراوح آعمارهم بين جr-هo عاماً، ممن يعانون من مضاعفات بعد إجراء العملية بفترة وجيزة. وقد آثتبت النتائج وجود توافق إيجابى بين الفحصين بنسبة ـع٪ بينما وصلت إيجابية الآشعة المقطعية مع سلبية الآشعة الفلورسينتية

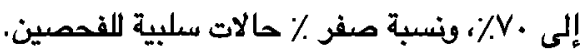

وتعدلت آنواع المضاعفات فيما بين نزيف نشط، تسريب، تجمع دموى، تجمع سوائل ، تجلط الطحال وجلطة الوريد البابى. وقد كان اللتسريب النسبة الآعلى.

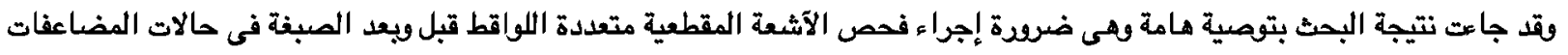
ما بعد عملية تكميم المعدة وذلك لما لها من آهمية كبيرة فى دقة الكثف المبكر عن هذه المضاعفات لما لذاتلك من تآثير إيجابى على التعامل الصحيح مع هذه المضاعفات المختلة. 